\title{
Evaluation of MUAC as a tool for assessing nutritional status during pregnancy (>20 weeks of gestation) among pregnant women in Delhi India
}

\author{
Megha Suresh
}

Department of Food and Nutrition, Lady Irwin College, University of Delhi, India

Swati Jain, $\mathrm{PhD}$

Department of Food and Nutrition, Lady Irwin College, University of Delhi, India

Neena Bhatia, $\mathrm{PhD}$ *

Department of Food and Nutrition, Lady Irwin College, University of Delhi, India

*Corresponding Author: neena.bhatia@lic.du.ac.in

\section{ABSTRACT}

The present study was conducted to assess the usefulness of MUAC as a screening tool to assess nutritional status during pregnancy ( $>20$ weeks). Pregnant women $(>20$ weeks of gestation, $n=100$ ) were enrolled from tertiary care ANC clinics in urban areas of Delhi. Data on socio-demographic profile was collected using pre-tested questionnaires. The blood pressure and anthropometric parameters (weight, height and MUAC) were recorded. The mean height, weight and MUAC of pregnant women were $152.15 \pm 4.93 \mathrm{~cm}, 56.7 \pm 6.7 \mathrm{Kgs}$ and 25.5 $\pm 2.60 \mathrm{~cm}$ respectively. Weight gain between trimesters and overall weight gain showed no correlation with blood pressure. Maternal weight was positively correlated with MUAC $(p=0.00)$, SBP $(p=0.006)$ and DBP $(p=0.02)$. Maternal height was negatively correlated with MUAC $(p=0.012)$. BMI and MUAC showed a significantly positive correlation $(p=0.00)$, which indicates the versatility of this tool. However, no association was observed between MUAC and blood pressure during pregnancy in the present study.

Key words: MUAC, Pregnant women, diet, blood pressure, gestation

$(\mathrm{ANC}=$ Antenatal Check-up, MUAC $=$ Mid-Upper Arm Circumference, $\mathrm{SBP}=$ Systolic Blood Pressure, $\mathrm{DBP}=$ Diastolic Blood Pressure) 


\section{INTRODUCTION}

In addition to being used among young children, mid-Upper Arm Circumference (MUAC) has been defined as, "an anthropometric measurement which is used to assess nutritional status and determine eligibility for nutritional support among adolescents and adults in low-resource settings, especially among pregnant women." (Tang et al. 2013). In particular, MUAC is often used as an indicator to assess maternal wasting. In addition, Endeshaw et al. (2016) found that women with MUAC $\geq 25.6 \mathrm{~cm}$ were twice as likely to have hypertensive disorders.

There are several advantages that must be considered while looking into MUAC as a screening tool; it is easier to measure and more convenient, requiring less expertise than assessment of BMI. It could possibly be used as an alternative for assessing the risk of poor pregnancy outcomes as well (Ricalde et al. 1998). Thus, in the settings where resources and expertise are scarce, MUAC could be reliably surrogated for BMI to assess the nutritional status in pregnant women (Fakier, Petro and Fawcus 2017; Okereke et al. 2013).

Although changes in MUAC are sometimes seen to be minimal during the entire duration of pregnancy, there is still a question of whether under certain circumstances MUAC could possibly relate well with gestational weight gain. There is evidence of lower gestational weight gain during pregnancy among women with lower values for MUAC than with higher MUAC values (NG et al. 2019). MUAC could also be related with measurement of fat deposition in pregnant women, specifically in middle-income urban Indian settings (Babu et al. 2020). In spite of the convenience and ease of measurement of MUAC, it requires careful training and supervision in order to locate the tape on the proper position in the arm; to use the non-dominant arm; to measure while the arm is straight, not bent; and to prevent wrapping the measuring tape too tightly or too loosely, any of which could result in an erroneous estimate and some degree of observer variability (Dasgupta et al. 2010).

There are various guidelines for the use of MUAC for classification of pregnant women as undernourished, normal or over nourished. The cut-off for malnutrition, according to the SPHERE Project varies from $<21 \mathrm{~cm}$ to $<23 \mathrm{~cm}$ in different countries (Charter 2011). For India, a commonly used guideline for moderate acute malnutrition is $19-22 \mathrm{~cm}$ and that of severe acute malnutrition is $<19 \mathrm{~cm}$ (National Revised Tuberculosis Guidelines INDIA 2017). Other cut-off values for maternal malnutrition in use include $<22.8 \mathrm{~cm}$ (Fakier, Petro and Fawcus 2017) and $<23 \mathrm{~cm}$ (National Department of Health, South Africa 2016). For obese pregnant women, only cut-off used is $>33 \mathrm{~cm}$ (National Department of Health, South Africa, 2016).

Pregnancy-induced hypertension is defined as either systolic blood pressure (SBP) more than $140 \mathrm{mmHg}$ or diastolic blood pressure (DBP) more than $90 \mathrm{mmHg}$ (Kintiraki 2015). There are certain factors that affect the onset of pregnancy induced hypertension (PIH). The risk of PIH increases as maternal pre-pregnancy BMI increases, irrespective of other obesity-associated comorbidity. Research shows that women $>20$ weeks of gestation are more prone to hypertensive disorders of pregnancy. Women with a history of chronic hypertension would possess a greater risk of getting PIH (Ehrenthal et al. 2011). Gaillard et al. (2011) found that the risk of pregnancy-induced hypertension and of preeclampsia increased among obese mothers and morbidly obese mothers and that excessive weight gain was associated with the risk of pregnancy-induced hypertension.

An increased incidence of pre-eclampsia is associated with obesity during pregnancy assessed by increased BMI and increased MUAC. Those women having a MUAC value $\geq 25.6 \mathrm{~cm}$ are 
two times more likely to have preeclampsia $(\mathrm{AOR}=2.49,95 \% \mathrm{CI}=1.58,3.94)$ (Endeshaw et al. 2014; Endeshaw et al. 2016). MUAC has a significant effect on blood pressure after delivery and during labour also (PS DK and Munir M 2020).

Limited data are available for use of MUAC for assessing overweight and obesity among pregnant women. Hence it is important to study the association between the MUAC and BMI. In addition, further information is needed on MUAC and blood pressure during pregnancy in the Indian setting.

\section{METHODS}

\section{Study design and locale}

This cross-sectional study was conducted at two government antenatal health care facilities (Lal Bahadur Shastri Hospital and Lady Hardinge Medical College) in Delhi, India from December 2018- January 2019. The sample size consisted of only 100 pregnant women due to time restrictions.

The inclusion criteria for participants were $>20$ weeks of gestation, residing in urban sites and visiting ANC clinics at LHMC/ Lal Bahadur Shastri Hospital, and willingness to participate. Those pregnant women with any serious health condition, on medication for any illness, or with complications like thyroid dysfunction were excluded from the study.

\section{Ethical clearance and consent of the subjects}

The study was approved by the Institutional Ethical Committee of Lady Irwin College, University of Delhi. The permission to the identified sites was facilitated through Maternal Health Division, Ministry of Health and Family Welfare, Government of India. The researcher approached the identified participants for the study and explained in detail about the study purpose and objectives. Study information sheet and consent form were written in Hindi. Informed consent was taken from the pregnant women either by thumb impression in the presence of a witness or by signature in case the mother was illiterate. The participants were free to withdraw from the study at any time.

\section{Tools and techniques used for data collection}

Height, weight and MUAC were taken using standardized equipment and techniques. The weight was measured using a calibrated digital weighing scale with an accuracy of $100 \mathrm{~g}$. Height was measured using stadiometer, with a sensitivity of $0.1 \mathrm{~cm}$. For the measurement of MUAC, a non-stretchable tape was used. The reading was taken with the tape still intact in its position (Gibson 2005). Blood pressure was measured using Omron digital blood pressure measuring machine and two readings were taken for each subject. Quality of the data was ensured by the use of standardized equipment, taking duplicate readings of each parameter, and training of the researcher for data collection. The pre-testing of tools was done on $10 \%$ of the total study sample in the identified study sites for data collection.

The data collected were coded, consolidated and transferred to excel sheets for analysis and interpretation. MUAC was categorised as per FANTA cut offs (Tang et al. 2016) and blood pressure was categorised according to ACOG (2017) guidelines. Anthropometric data and blood pressure values were analysed using Microsoft excel (2010) and SPSS 21 in terms of mean, frequencies, range, minimum and maximum values, correlations. Statistical tests used 
were Pearson correlation coefficient, Spearman correlation coefficient, t-test, and MannWhitney test. Mean and standard deviations of anthropometric measurements such as height, weight, weight gain, and MUAC were calculated. All the results were tested at 5\% level of significance.

\section{RESULTS AND DISCUSSION}

\section{Nutritional status of pregnant women}

The anthropometric measurements of these pregnant women are presented in Table 1.

Table 1. Anthropometric details of pregnant women

\begin{tabular}{|c|c|c|}
\hline S.no & Measurements & Values \\
\hline $\mathbf{1}$ & Height (cm) & $152.15 \pm 4.93$ \\
\hline & Mean \pm SD & 151.8 \\
\hline & Median & $137.9-163.3$ \\
\hline 2. & Range & $56.7 \pm 6.7$ \\
\hline & Weight (Kg) & 57 \\
\hline & Mean \pm SD & $40-74.7$ \\
\hline & Median & $25.5 \pm 2.60$ \\
\hline 3. & Range & 25.3 \\
\hline & MUAC (cm) & $19.2-32.5$ \\
\hline & Mean \pm SD & \\
\hline & Median & \\
\hline
\end{tabular}

Percent of ideal body weight-for-height by week of pregnancy was calculated using Gueri, Jutsum \& Sorhaindo (1982) criteria for assessment of nutritional status during pregnancy (Table 2).

Table 2. Classification of pregnant women as percent of ideal body weight for height by weeks of gestation

\begin{tabular}{|c|c|c|}
\hline $\begin{array}{c}\text { \%Ideal body } \\
\text { weight }\end{array}$ & $\begin{array}{c}\text { Number of pregnant } \\
\text { women (n) }\end{array}$ & $\begin{array}{c}\text { Percentage of pregnant } \\
\text { women (\%) }\end{array}$ \\
\hline $60-70$ & 2 & 2 \\
\hline $70-80$ & 14 & 14 \\
\hline $80-90$ & 16 & 16 \\
\hline $90-100$ & 34 & 34 \\
\hline $100-110$ & 12 & 12 \\
\hline $110-120$ & 6 & 6 \\
\hline Data not known & 14 & 14 \\
\hline
\end{tabular}

Table 3 and Table 4 depict the assessment of nutritional status of pregnant women based on MUAC. As evident from Table 3, a majority of these pregnant women were not at nutritional risk $(86 \%)$, while $14 \%$ were mild to moderately undernourished. Table 4 depicts further classification of those with MUAC $\geq 23 \mathrm{~cm}$. 
Table 3. Nutritional status of pregnant women according to MUAC cut-offs

\begin{tabular}{|c|c|c|c|}
\hline CATEGORIES & $\begin{array}{c}\text { MUAC CUT } \\
\text { OFF* } \\
(\mathrm{cms})\end{array}$ & $\begin{array}{c}\text { Number of } \\
\text { pregnant women } \\
(\mathrm{N}=100)\end{array}$ & $\begin{array}{c}\text { \% of } \\
\text { pregnant } \\
\text { women }\end{array}$ \\
\hline Severe undernourished & $<19$ & 0 & 0 \\
\hline $\begin{array}{c}\text { Mild to moderate } \\
\text { undernourished }\end{array}$ & $19-22$ & 14 & 14 \\
\hline Normal & 23 or above & 86 & 86 \\
\hline
\end{tabular}

* Source: FANTA 2016

Table 4. Distribution of pregnant women among those with $M U A C \geq 23 \mathrm{~cm}(\mathrm{n}=86)$

\begin{tabular}{|c|c|c|}
\hline $\begin{array}{c}\text { MUAC CUT OFF } \\
(\mathrm{cms})\end{array}$ & $\begin{array}{c}\text { Number of pregnant } \\
\text { women }(\mathrm{N}=100)\end{array}$ & $\begin{array}{c}\text { \% of pregnant } \\
\text { women }\end{array}$ \\
\hline $23-25.99$ & 42 & 42 \\
\hline $26-28.99$ & 35 & 35 \\
\hline $29-31.99$ & 6 & 6 \\
\hline $32-34.99$ & 3 & 3 \\
\hline
\end{tabular}

A total of 14 of these pregnant women were hypertensive, with either systolic blood pressure or diastolic blood pressure above the cut-off value. Out of these, 4 had both systolic and diastolic blood pressure above the cut-off value.

\section{Association between maternal anthropometric measurements}

Table 5 illustrates association between height, weight with MUAC and Blood pressure.

Table 5. Associations between of height, weight, MUAC, and blood pressure

\begin{tabular}{|l|l|l|l|l|l|l|}
\hline & \multicolumn{2}{|l|}{ MUAC } & \multicolumn{3}{l|}{ Systolic blood pressure } & Diastolic blood pressure \\
\hline & $\begin{array}{l}\text { Pearson } \\
(\mathrm{r})\end{array}$ & $\begin{array}{l}\text { Significance } \\
(\mathrm{p})\end{array}$ & $\begin{array}{l}\text { Pearson } \\
(\mathrm{r})\end{array}$ & $\begin{array}{l}\text { Significance } \\
(\mathrm{p})\end{array}$ & $\begin{array}{l}\text { Pearson } \\
(\mathrm{r})\end{array}$ & $\begin{array}{l}\text { Significance } \\
(\mathrm{p})\end{array}$ \\
\hline $\begin{array}{l}\text { Height } \\
(\mathrm{cms})\end{array}$ & -0.25 & $\mathbf{0 . 0 1 2}$ & -0.11 & 0.28 & -0.04 & 0.64 \\
\hline $\begin{array}{l}\text { Weight } \\
(\mathrm{kg})\end{array}$ & 0.64 & $\mathbf{0 . 0 0}$ & 0.29 & $\mathbf{0 . 0 0 6}$ & 0.25 & $\mathbf{0 . 0 2}$ \\
\hline MUAC & - & - & 0.63 & 0.53 & 0.07 & 0.47 \\
\hline
\end{tabular}

*in these cases, Spearman correlation coefficient is calculated as these are ordinal data.

Several studies have shown that Shobeiri \& Nazari (2006) found a correlation between MUAC and maternal weight at term. Olukoya \& Giwa-Osagie (1991) found that the sensitivity and positive predictive value of mid-arm circumference less than $23 \mathrm{~cm}$ for first trimester weight of less than $45 \mathrm{~kg}$ was $85.7 \%$ and $54.5 \%$ respectively. In the second trimester, these values for mid-arm circumference of less than $24 \mathrm{~cm}$ and weight less than $50 \mathrm{~kg}$ were $55.6 \%$ and $32.3 \%$ respectively.

The correlation between MUAC and BMI at $>20$ weeks of pregnancy in the present study was $0.534(\mathrm{p}<.000)$. 
This suggests that MUAC may be useful for assessing nutritional status at $>20$ weeks of pregnancy. Earlier studies, have also shown strong associations between MUAC and BMI in women of reproductive age (Khadivzadeh 2002, Jeyakumar, Ghugre \& Gadhave 2013).

\section{CONCLUSION}

The present study shows that MUAC can be potentially used as an indicator for nutritional status of pregnant women under certain circumstances. MUAC was positively correlated with maternal weight $(\mathrm{p}=0.00)$ and BMI $(\mathrm{p}=0.00)$ which implies that with an increase in maternal weight, MUAC would also increase. Conversely, MUAC showed a negative correlation with maternal height $(\mathrm{p}=0.012)$. However, MUAC did not show any significant correlation with SBP and DBP, possibly due to the small sample size. This suggests the need to further validate the usefulness of MUAC as a substitute marker for assessing the nutritional status during pregnancy ( $>20$ weeks of gestation).

\section{Limitations of the study}

1) In the study, confounding variables such as age, gravida, parity could not be controlled.

2) The sample size of the study was small.

3) 14 women could not be contacted for body weight measurements at the health centre, hence that data was missing for them.

\section{REFERENCES}

Ananth CV and Basso O 2010. "Impact of pregnancy-induced hypertension on stillbirth." Epidemiology 21(1):118-123. DOI: 10.1097/EDE.0b013e3181c297af

ACOG (American College of Obstetricians and Gynaecologists) 2017. Blood pressure guidelines.

Charter H 2011. "The Sphere Project"

Dasgupta A, Butt A, Saha TK, Basu G, Chattopadhyay A and Mukherjee A 2010.

"Assessment of malnutrition among adolescents: Can BMI be replaced by MUAC", Indian Journal ff Community Medicine, 35(2):276. DOI: 10.4103/0970-0218.66892

Ehrenthal DB, Jurkovitz C, Hoffman M, Jiang X and Weintraub WS 2011. "Prepregnancy body mass index as an independent risk factor for pregnancy induced hypertension." Journal of Women's Health, 20(1):67-72. DOI: https://doi.org/10.1089/jwh.2010.1970

Endeshaw M, Abebe, F, Worku, S, Menber, L, Assress, M and Assefa, M 2016. "Obesity in young age is a risk factor for preeclampsia: a facility based case-control study, northwest Ethiopia.” BMC Pregnancy and Childbirth, 16(1):1-11.

Endeshaw M, Ambaw F, Aragaw A and Ayalew A 2014. "Effect of maternal nutrition and dietary habits on preeclampsia: a case-control study." International Journal of Clinical Medicine, 5(21): 1405.

Fakier A, Petro G and Fawcus S 2017. "Mid-upper arm circumference: A surrogate for body mass index in pregnant women." South African Medical Journal, 107(7):606-610. 
Gaillard R, Steegers EA, Hofman A and Jaddoe VW 2011. "Associations of maternal obesity with blood pressure and the risks of gestational hypertensive disorders. The Generation R Study.” Journal of Hypertension, 29(5):937.

DOI: $10.1097 /$ HJH.0b013e328345500c

Gueri M, Jutsum P and Sorhaindo B 1982. "Anthropometric assessment of nutritional status in pregnant women: a reference table of weight-for-height by week of pregnancy." The American Journal of Clinical Nutrition, 35(3):609- 616.

DOI: https://doi.org/10.1093/ajcn/35.3.609

Indriyani R, Hannan M and Hidayat S 2020. "Risk factors for low birth weight in Puskesmas Ganding." European Journal of Molecular and Clinical Medicine, 7(7):21-27.

Jeyakumar A, Ghugre P and Gadhave S 2013. "Mid-Upper-Arm Circumference (MUAC) as a Simple measure to assess the nutritional status of adolescent girls as compared with BMI.” Infant, Child, and Adolescent Nutrition, 5(1):22- 25.

DOI: https://doi.org/10.1177/1941406412471848

Khadivzadeh T 2002. Mid upper arm and calf circumferences as indicators of nutritional status in women of reproductive age. EMHJ-Eastern Mediterranean Health Journal, 8(45):612-618.

Kintiraki E, Papakatsika S, Kotronis G, Goulis DG and Kotsis V 2015. "Pregnancyinduced hypertension." Hormones, 14(2):211-223.

Kruger HS 2005. "Maternal anthropometry and pregnancy outcomes: a proposal for the monitoring of pregnancy weight gain in outpatient clinics in South Africa." Curationis, 28(4):40-49. DOI: https://doi.org/10.4102/curationis.v28i4.1012

National Department of Health, South Africa 2016. Guidelines for Maternity Care in South Africa: A Manual for Clinics, Community Health Centres and District Hospitals.

Ng CM, Badon SE, Dhivyalosini M, Hamid JJM, Rohana AJ, Teoh AN and Satvinder K 2019. "Associations of Pre-Pregnancy Body Mass Index, Middle- 61 Upper Arm Circumference, and Gestational Weight Gain", Sexual and Reproductive Healthcare, 20:60-65. DOI: https://doi.org/10.1016/j.srhc.2019.03.002

Okereke CE, Anyaehie UB, Dim CC, Iyare EE and Nwagha UI 2013. "Evaluation of some anthropometric indices for the diagnosis of obesity in pregnancy in Nigeria: a crosssectional study" African Health Sciences, 13(4):1034-1040. DOI: 10.4314/ahs.v13i4.25

Olukoya AA and Giwa-Osagie OF 1991. "Maternal weight and weight gain during pregnancy--can the arm circumference be used as surrogate?" African Journal of Medicine and Medical Sciences, 20(2):155-162.

PS, DK and Munir M 2020. "The effect of nutritional status to the blood volume at labor and postpartum blood pressure." International Journal of Public Health and Clinical Sciences, 7(1):124-130. DOI: https://doi.org/10.32827/ijphcs.7.1.124

Ricalde AE, Velásquez-Meléndez G, Tanaka ACDA and de Siqueira AA 1998. "Midupper arm circumference in pregnant women and its relation to birth weight." Revista de Saude Publica, 32:112-117. 
Shobeiri F and Nazari M 2006. "Patterns of weight gain and birth weight amongst Indian women.” Iranian Journal of Medical Sciences, 31(2):94-97.

Tang AM, Dong K, Deitchler M, Chung M, Maalouf-Manasseh, Z, Tumilowicz, A and Wanke, C 2013. "Use of cutoffs for mid-upper arm circumference (MUAC) as an indicator or predictor of nutritional and health-related outcomes in adolescents and adults: a systematic review." Washington, DC: FHI 360/FANTA.

http://citeseerx.ist.psu.edu/viewdoc/download?doi=10.1.1.660.4448\&rep=rep1\&type=pdf

Tang AM, Chung M, Dong K, Terrin N, Edmonds A, Assefa, N and Maalouf-Manasseh Z 2016. "Determining a global mid-upper arm circumference cutoff to assess malnutrition in pregnant women." Washington, DC: FHI 360/Food and Nutrition Technical Assistance III Project (FANTA).

https://www.researchgate.net/profile/Nega-

Assefa/publication/305463673_Determining_a_Global_Mid-

Upper_Arm_Circumference_Cutoff_to_Assess_Malnutrition_in_Pregnant_Women/links/ 578f943408aecbca4caddad5/Determining-a-Global-Mid-Upper-Arm-Circumference-

Cutoff-to-Assess-Malnutrition-in-Pregnant-Women.pdf 